\title{
RANCANG BANGUN SISTEM INFORMASI MANAJEMEN DISPOSISI SURAT MENYURAT DENGAN MENGGUNAKAN MODEL RAD (RAPID APPLICATION DEVELOPMENT)
}

\author{
Instianti Elyana ${ }^{1}$, Ishak Kholil ${ }^{2}$, Frans Eduard Schaduw ${ }^{3}$ \\ ${ }^{1}$ Administrasi Bisnis \\ Universitas Bina Sarana Informatika \\ www.bsi.ac.id \\ instianti.iny@bsi.ac.id \\ 2 Sistem Informasi, STMIK Nusa Mandiri \\ www.nusamandiri.ac.id \\ ishak.ihk@nusamandiri.ac.id \\ ${ }^{3}$ Administrasi Bisnis \\ Universitas Bina Sarana Informatika \\ www.bsi.ac.id \\ frans.fes@bsi.ac.id
}

\begin{abstract}
Many numbers of letters are made and accepted in the administrative administration section, so that data search will be inefficient in terms of time and energy using a manual system. So that at this time a more structured letter management administration system is needed in order to speed up the search for existing data and create reports. This filing application has the following capabilities: this filing application is run on a personal computer network in the administrative space, administrative officers can access this filing application by entering the correct user login, can add, edit, cancel, delete and save incoming mail and out, can search incoming letters and outgoing letters based on the sender and subject matter, search results can be sorted according to the letter id or date of the letter, can print reports based on search results that have been done based on the letter id or date of the letter. Using the RAD model will make it easier to design a correspondence Disposition Information System.
\end{abstract}

\section{Keywords: Correspondence Letter, Outgoing Letter, Entry Letter, Administration}

\begin{abstract}
Abstrak-Banyak jumlah surat yang dibuat dan diterima dibagian administrasi tata usaha, sehingga pencarian data akan menjadi tidak efisien dalam hal waktu dan tenaga dengan menggunakan sistem manual. Sehingga pada saat ini diperlukan suatu sistem administrasi manajemen surat yang lebih terstruktur agar dapat mempercepat pencarian data yang ada dan pembuatan laporan. Aplikasi kearsipan ini mempunyai kemampuan sebagai berikut: aplikasi kearsipan ini dijalankan pada jaringan personal komputer pada bagian ruang tata usaha, petugas tata usaha dapat mengakses aplikasi kearsipan ini dengan memasukkan login user yang benar, dapat melakukan menambah, mengedit, membatalkan, menghapus dan menyimpan surat masuk dan keluar, dapat melakukan pencarian surat masuk dan surat keluar berdasarkan pengirim dan perihal, hasil pencarian dapat dilakukan pengurutan berdasar id surat atau tanggal surat, dapat mencetak laporan berdasarkan hasil pencarian yang telah dilakukan berdasarkan id surat atau tanggal surat. Dengan menggunakan model RAD akan lebih memudahkan dalam perancangan Sistem informasi Disposisi Surat menyurat.
\end{abstract}

\section{Kata Kunci:Surat Menyurat, Surat Keluar, Surat Masuk, Administrasi}

\section{PENDAHULUAN}

Surat menyurat merupakan hal yang tidak dapat dihindari dalam suatorganisasi/perusahaan karena hal ini memegang peranan penting dalam proses administrasi. Surat merupakan rekaman kegiatan ataupun peristiwa dalam suatu instasi yang harus tersimpan dalam jangka waktu tertentu untuk kebutuhan tertentu. Manajemen surat menyurat dibutuhkan untuk mengatur 
jalannya suatu prosedur dalam suatu perusahaan, agar surat tertata baik dan tidak tercecer yang berdampak pada kerugian bagi perusahaan(Ferdinandus, Sandy, 2012).

Pengelolaan surat masuk dan surat keluar dikatakan penting karena banyak informasi yang dibutuhkan perusahaan. Data surat masuk dan surat keluar harus tersimpan dengan baik agar dapat memudahkan dalam pengelolaannya. Pengelolaan surat masuk dan surat keluar yang menggunakan cara manual (Saputra \& Famukhit, 2014) yaitu dengan melakukan pencatatan data surat kedalam buku kendalanya adalah apabila buku tersebut hilang atau rusak maka data pun akan ikut hilang. Dan jika pihak perusahaan menyimpan dokumen fisik surat yang ada akan ikut hilang dan rusak menyulitkan perusahaan dalam mencari dokumen surat yang dibutuhkan.

Peran sebuah tool dalam pengolahan data dan memiliki peran yang sangat penting bagi sebuah organisasi/perusahaan, tentu tool yang dimaksud adalah sebuah system informasi yang bertugas mengelola data dengan jumlah yang relative cukup banyak setiap harinya, apalagi disebuah organisasi/perusahaan besar pasti memerlukan suatu alat bantu yang memiliki tingkat kecepatan perhitungan dan penyampaian data yang tinggi. Alat bantu tersebut berupa perangkat keras dan perangkat lunak. Keunggulan aplikasi berbasis komputer untuk memproses data akan meningkatkan efektifitas dan produktifitas, serta efisiensi proses dan prosedur yang ada diorganisasi/perusahaan. Pengunaan Sistem aplikasi pengelolaan surat masuk dan surat keluar pada PT Angkasa Pura 1 Semarang sudah menggunakan sistem informasi yang terkomputerisasi baik pada penginputan, pencarian data surat masuk/ surat keluar dan pembuatan laporan dapat dilakukan kapan saja dalam waktu yang cepat karena data tersimpan dengan aman dan terstruktur serta tidak terjadi lagi keterlambatan dalam pencarian data. (Sugiharti \& Triliani, 2015).

Permasalahan surat menyurat dengan sistem konvensional pernah dibahas pada studi kasus Kantor Desa Tanjungsari Kotawinangun Kebumen ini adalah dimana bentuk pelayanan surat menyuratnya masih menggunakan sistem yang konvensional (Priyadi \& Lestari, 2018). Bentuk permasalahan yang sering timbul adalah sulitnya pelaporan surat masuk (Suherman, 2017) dan keluar dan pencariaan data surat masuk dan surat keluar,

Pada era informasi saat ini, permasalahan yang sering timbul akibat dari belum termanfaatkannya teknologi dengan baik, Teknologi harus dapat menjadi solusi permasalahan tersebut. Yaitu bagaimana mengolah data sedemikian rupa untuk menghasilkan informasi yang berguna, dan mudah digunakan oleh pengguna informasi (Sasongko \& Diartono, 2009).

Untuk itu dibutuhkan pemanfaatan teknologi informasi untuk mendukung proses administrasi surat menyurat hal ini tentu untuk mempercepat pembuatan laporan dan pencarian data. Karena itu perlu dibangun suatu sistem untuk pengelolaan dan pengarsipan berkas-berkas surat yang berupa aplikasi kearsipan untuk memudahkan dalam sistem surat menyurat dalam sebuah perusahaan. Berdasarkan kebutuhan perusahan adalah membuat perangkat lunak untuk workflow pengelolaan surat menyurat lebih khususnya pada bagian pengelolan surat masuk dan keluar.

Pengembangan sebuah perangkat tentu harus didukung oleh metode yang tepat, Unified modeling Language (UML) dapat membantu tim pengembangan proyek berkomunikasi, mengeksplorasi potensi desain, dan memvalidasi desain arsitektur perangkat lunak atau pembuat program. Komponen atau notasi UML diturunkan dari 3 (tiga) notasi yang telah ada sebelumnya yaitu Grady Booch, OOD (Object-Oriented Design), Jim Rumbaugh, OMT (Object Modelling Technique), dan Ivar Jacobson OOSE ObjectOriented Software Engineering)(Haviluddin, 2013).

\section{BAHAN DAN METODE}

Langkah-langkah penelitian dapat dilihat pada diagram berikut ini :

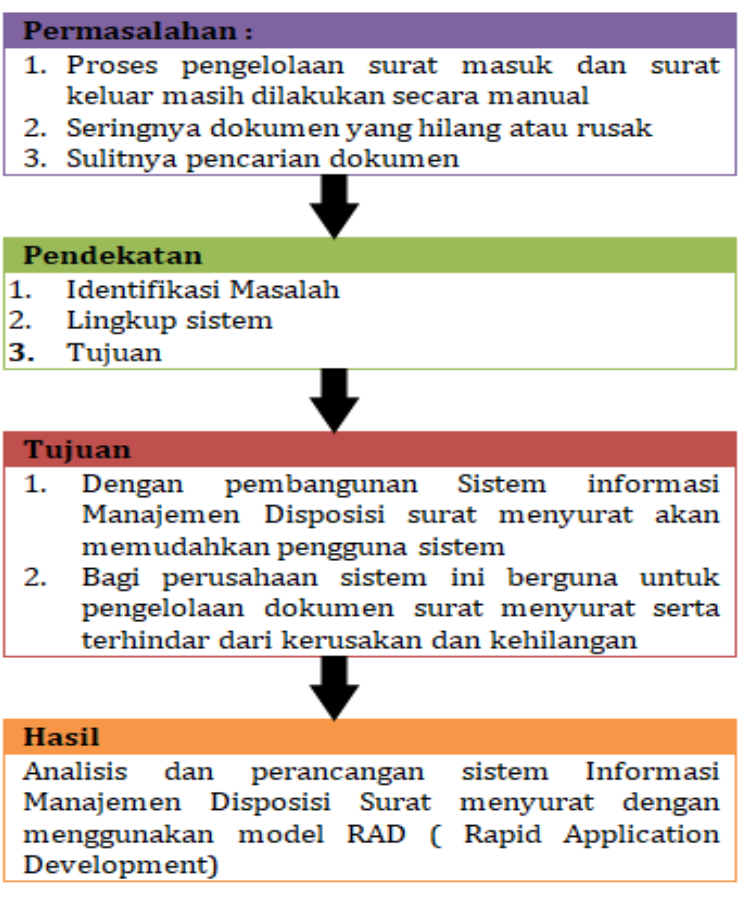

Gambar 1. Bagan Penelitian 


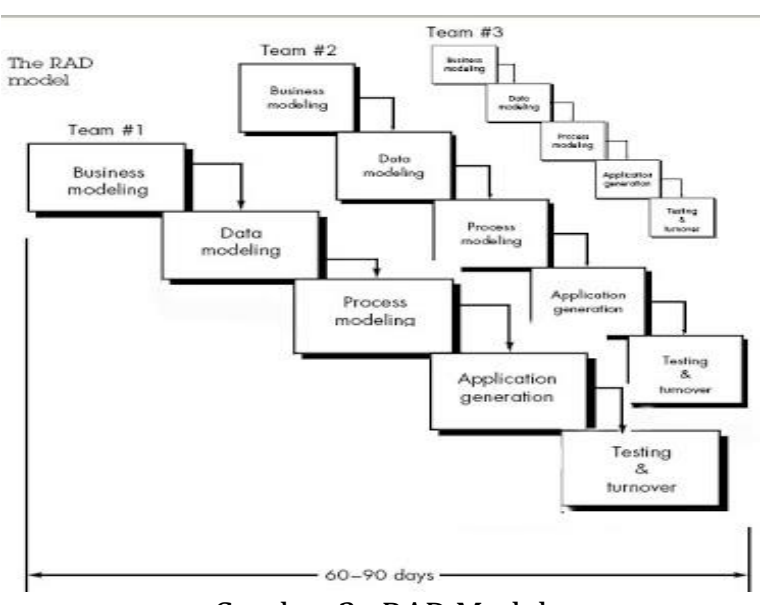

Gambar 2 : RAD Model

Business Modeling

Aliran informasi antar fungsi bisnis dimodelkan dalamcara yang menjawab pertanyaan-pertanyaan berikut: Informasi apa yang mendorong bisnis proses? Informasi apa yang dihasilkan? Siapa yang menghasilkannya? Kemana perginya informasi? Siapa yang memprosesnya?

Data Modeling

Aliran informasi didefinisikan sebagai bagian dari fase pemodelan bisnis disempurnakan menjadi satu set objek data yang diperlukan untuk mendukung bisnis acteristics (disebut atribut) dari setiap objek diidentifikasi dan hubungan antara objek-objek ini didefinisikan

Proces Modeling

Objek data yang didefinisikan dalam fase pemodelan data ditransformasikan untuk mencapai aliran informasi yang diperlukan untuk mengimplementasikan fungsi bisnis. Memproses deskripsi dibuat untuk menambah, mengubah, menghapus, atau mengambil a objek data.

\section{Application Generation.}

RAD mengasumsikan penggunaan teknik generasi keempat (Bagian 2.10). Daripada membuat perangkat lunak menggunakan generasi ketiga konvensional bahasa pemrograman proses RAD bekerja untuk menggunakan kembali komponen program yang ada (bila memungkinkan) atau membuat komponen yang dapat digunakan kembali (bila perlu). Dalam semua kasus, alat otomatis digunakan untuk memfasilitasi pembangunan perangkat lunak.

Testing and Turnover

Karena proses RAD menekankan penggunaan kembali, banyak komponen program telah diuji. Ini mengurangi waktu pengujian keseluruhan. Namun, komponen baru harus diuji dan semua antarmuka harus dilakukan sepenuhnya.

\section{HASIL DAN PEMBAHASAN}

Model RAD mengadopsi model waterfall dan pembangunan dalam waktu singkat yang dicapai dengan penerapan :

1. component based construktion ( pemprograman berbasis komponen bukan prosedural )

2. penekanan pada penggunaan ulang ( reuse ) komponen perangkat lunak yang telah ada.

3. pembangkitan kode program otomatis atau semi otomatis

4. multiple (banyak team)

\section{Business Modeling}

Prosedur surat masuk

Surat masuk dari pengirim baik dari luar atau pun melalui email kemudian diterima oleh administrasi FO yang akan di catat data surat masuk dan surat keluar pensortiran surat, disposisi surat serta pengarsipan dan penerimaan surat keluar, pensortiran surat, pengiriman serta pengarsipan.

\section{Prosedur surat keluar}

Surat surat yang keluar akan dicatat oleh administrasi Fo dimasukkan kedalam sistem kemudian diberikan no surat barulah surat akan keluar ketujuan masing-masing.

\section{Laporan surat menyurat}

Surat menyurat akan diinformasikan ke perusahaan melalui sistem informasi disposisi surat masuk dan surat keluar dibangun untuk memudahkan pengguna sistem manajemen disposisi dapat tersimpan dan terkelola dengan baik.

\section{Data Modelling}

Sistem Informasi Disposisi Surat ini dimulai surat yang diterima oleh administrasi untuk disortir berdasarkan tujuan surat yang harus dicatat pada form/buku surat masuk, Surat akan didisposisikan ke tujuan masing-masing. Begitupun dengan surat yang keluar akan dicatat oleh admin berdasarkan tujuan surat tersebut.

Tujuan utama memahami alur bisnis dan segala pengetahuan yang terkait operasional proses surat menyurat

\section{ERD ( Entity Relationship Diagram)}

Model ini dimaksudkan untuk menjelaskan hubungan antar data dalam basis data berdasarkan objek-objek dasar data yang mempunyai hubungan antar relasi. Dari hasil pengamatan surat menyurat di suatu perusahaan dibuat lah ERD dengan penggambaran sebagai berikut : 


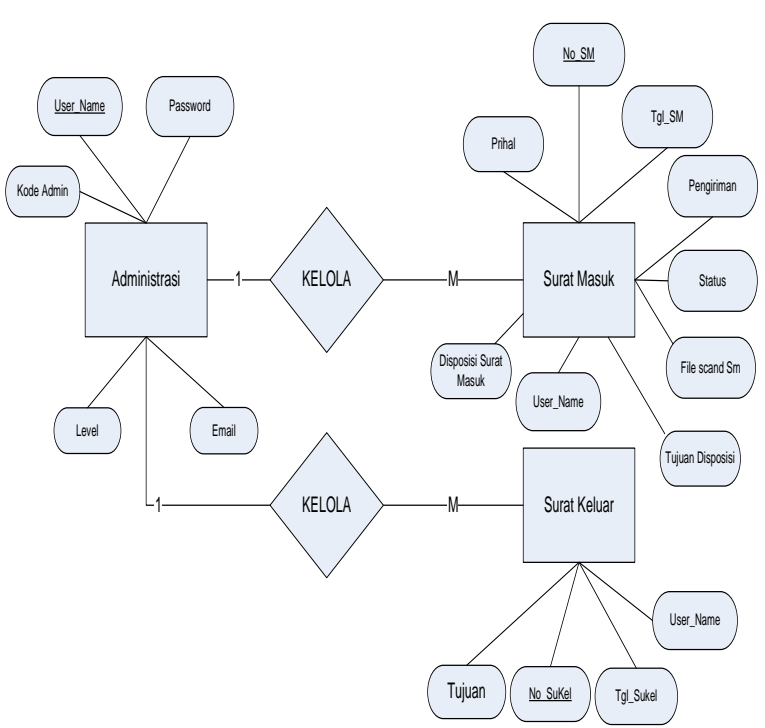

Gambar 5. Rancangan ERD

Semua surat yang masuk dan keluar diterima dan diteliti tujuannya adalah untuk memudahkan dibuka dan dicatatnya informasi kedalam lembar kendali surat masuk dan keluar yang telah disediakan oleh sistem informasi. Proses disposisi surat oleh pengolah mengikuti aturan dan pola yang telah disepakati.

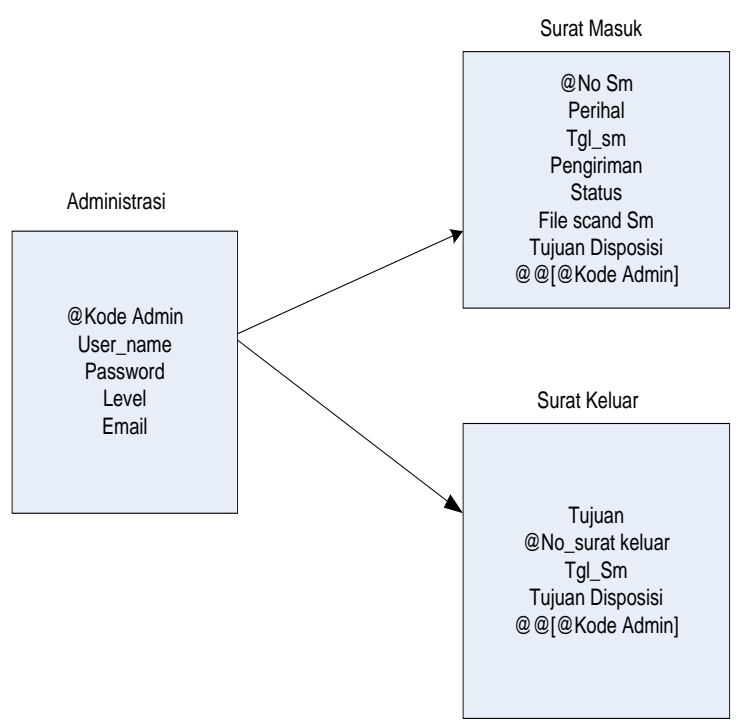

Gambar 6. Rancangan LRS

\section{Proses Modeling}

Dalam proses modeling menggunakan Unified Modeling Language (UML)

Pemodelan mengunakan UML dapat memberikan gambaran pada sistem yang penulis bahas yaitu Surat yang diterima oleh administrasi akan disortir terlebih dahulu untuk mengetahui tujuan surat, seletah proses sortir surat akan disiposisikan kebagian/divisi tujuan surat, dan administrasi mencatat dokumentasi penerimaannya sebagai arsip. Sedangkan untuk surat keluar, administrasi menerima surat yang dibuat oleh bagian/divisi, untuk dilakukan sortir tujuan surat agar tertulis alamat yang jelas, setelah dilakukan sortir surat akan dikirim melalui kurir, dan administrasi mengarsipkan bukti surat keluar.. Metode ini juga bertujuan menyatukan teknik pemodelan berorientasi objek yang terstandarisasi.

Sistem informasi Disposisi Surat ini adalah dimulai surat yang diterima oleh admin untuk disortir berdasarkan tujuan surat yang harus dicatat pada form/buku surat masuk, Surat akan didisposisikan ke tujuan masing-masing. Begitupun dengan surat yang keluar akan dicatat oleh admin berdasarkan tujuan surat tersebut.

\section{Requirement}

Untuk mengambarkan kebutuhan dari sebuah system dengan mengunakan use case diagram menggambarkan manfaat system jika dilihat menurut pandangan orange yang berada diluar system ( actor ). Diagram ini menjelaskan fungsionalitas suatu system atau kelas dan bagian system berinteraksi dengan dunia luar.

Komponen pembentuk diagram use case adalah:

a. Aktor menggambarkan pihak-pihak yang berperan dalam system.

b. Use Case aktifitas atau sarana yang disiapkan oleh bisnis atau system.

Hubungan link actor mana saja yang terlibat dalam use case ini.

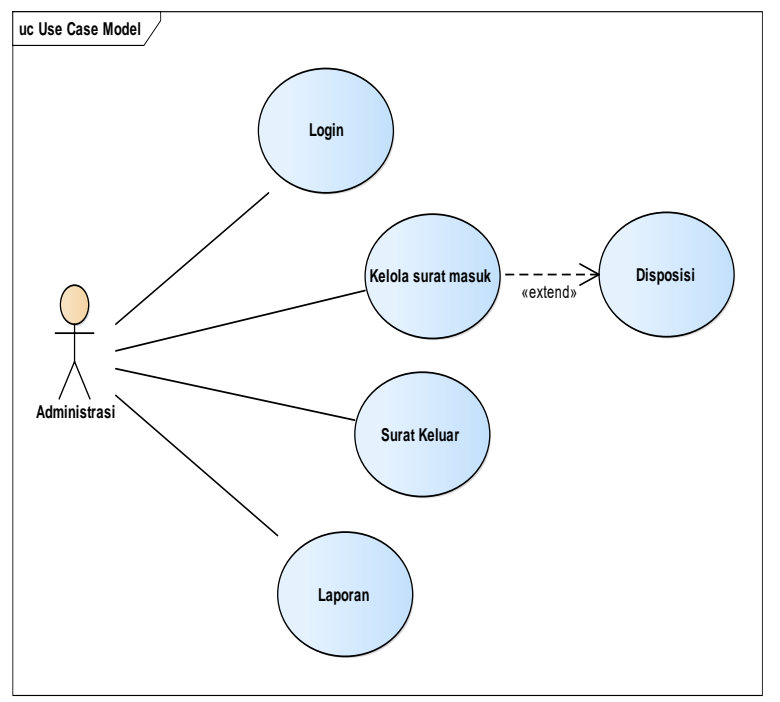

Gambar 3. Rancangan Use Case

\section{Activity diagram}

Diagram aktiftas lebih memfokuskan diri pada eksekusi dan alur system dari pada bagaimana system dari pada bagaimana system ini dirakit. Diagram ini tidak hanya memodelkan software melainkan memodelkan model bisnis 
juga. Diagram aktivitas menunjukkan aktivitas system dalam bentuk kumpulan aksi-aksi.

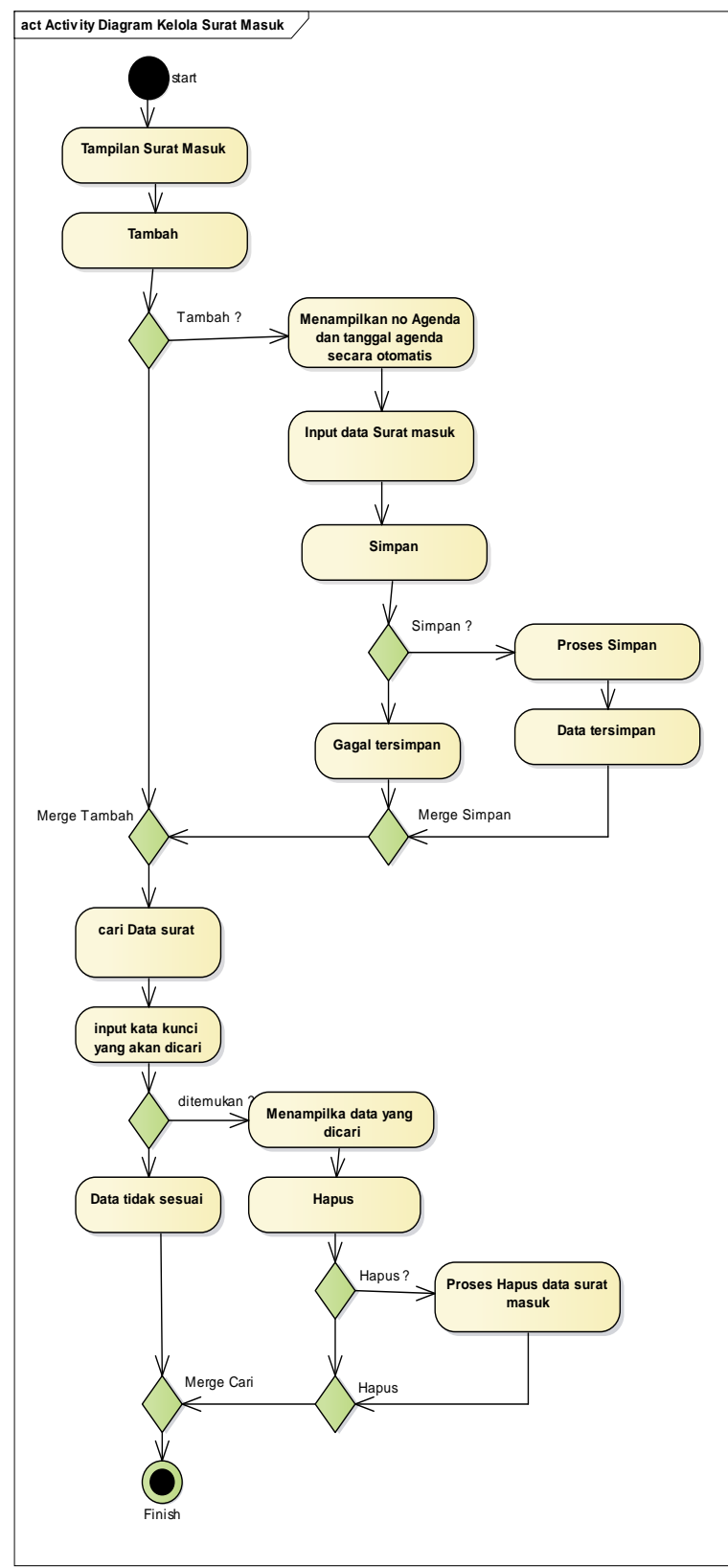

Sumber : Hasil penelitian, 2019

Gambar 4. Rancangan Activity Diagram Proses

\section{Application Generation}

Data- data sistem pengolahan data memerlukan interface masukkan ( Input ). Dimana data-data membentuk keluaran output dalam bentuk informasi.

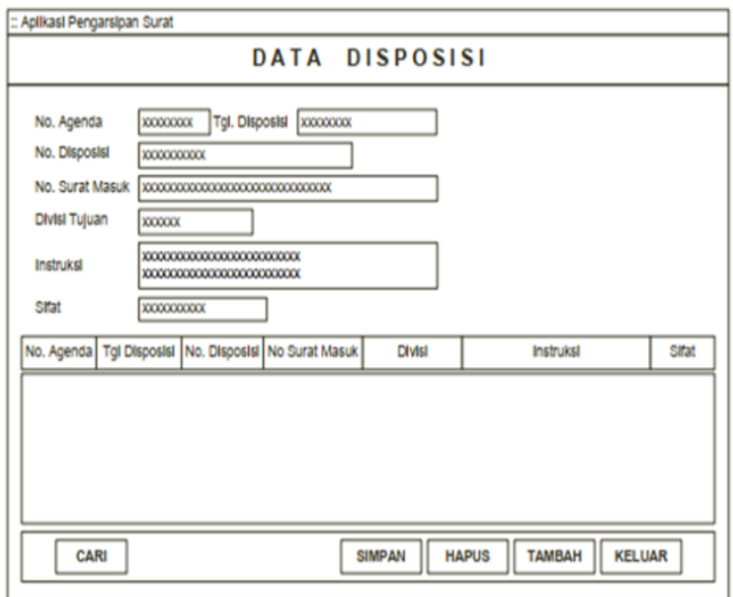

Sumber : ( Hasil Penelitian, 2019)

Gambar 8. Desain input data disposisi

Desain input data disposisi digunakan untuk menginput, menambahkan, mencari data surat masuk dan menghapus. Dengan memasukkan no agenda kemudian surat akan dapat mudah untuk dapat mencarinya.

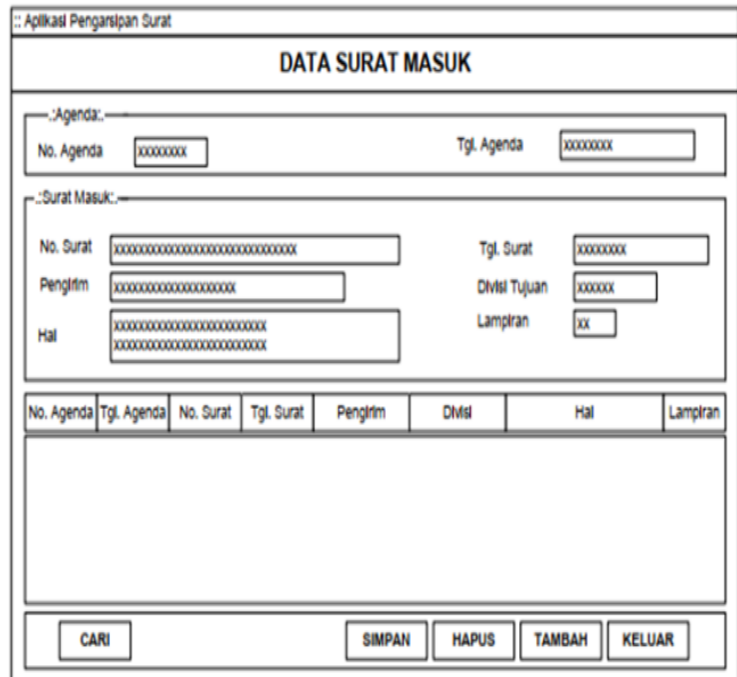

Sumber : ( Hasil Penelitian, 2019)

Gambar 9. Desain input data surat masuk

Desain input data surat masuk dengan memasukkan data surat input no agenda, tanggal agenda dan memasukkan no surat. Desain ini memudahkan untuk mencari surat masuk dapat juga untuk menghapus, menyimpan, mencari dan menambahkan surat dengan tetap menggunakan no agenda. 


\section{Testing and turnover}

Testing login

\begin{tabular}{llllll}
\hline No & Sekenario pengujian & Test Case & \multicolumn{1}{l}{ Hasil yang diharapkan } & $\begin{array}{l}\text { Hasil } \\
\text { pengujian }\end{array}$ & Kesimpulan \\
\hline 1 & $\begin{array}{l}\text { Mengosongkan Semua } \\
\text { field yang berada di } \\
\text { halaman baru }\end{array}$ & $\begin{array}{l}\text { Semua field atau } \\
\text { semua text box } \\
\text { kosong }\end{array}$ & $\begin{array}{l}\text { Sistem akan menolak akses jika no } \\
\text { agenda tidak dimasukkan }\end{array}$ & $\begin{array}{l}\text { Sesuai } \\
\text { harapan }\end{array}$ & Valid \\
& $\begin{array}{l}\text { Hanya mengisi 5 field saja } \\
\text { lalu klik cari }\end{array}$ & $\begin{array}{l}\text { No.agenda : 1231, } \\
\text { tanggal agenda: } 6 \\
\text { agustus 2019, } \\
\text { no.surat : 1444, } \\
\text { sisanya kosong }\end{array}$ & $\begin{array}{l}\text { Sistem akan menolak akses Daftar dan } \\
\text { menampilkan Pesan “Kesalahan pada } \\
\text { pengisian form (masih kosong)” }\end{array}$ & $\begin{array}{l}\text { Sesuai } \\
\text { harapan }\end{array}$ & Valid \\
& Semua field di isi & Sistem menerima akses & Sesuai & Harapan & Valid \\
\hline 3
\end{tabular}

Testing Masuk

\begin{tabular}{|c|c|c|c|c|c|}
\hline No & Sekenario pengujian & Test Case & Hasil yang diharapkan & $\begin{array}{l}\text { Hasil } \\
\text { pengujian }\end{array}$ & Kesimpulan \\
\hline 1 & $\begin{array}{l}\text { Mengosongkan Semua } \\
\text { field yang berada di } \\
\text { halaman baru }\end{array}$ & $\begin{array}{lrr}\text { Semua field } & \text { atau } \\
\text { semua } & \text { text box } \\
\text { kosong } & & \\
\end{array}$ & $\begin{array}{l}\text { Sistem akan menolak akses jika no } \\
\text { agenda tidak dimasukkan }\end{array}$ & $\begin{array}{l}\text { Sesuai } \\
\text { harapan }\end{array}$ & Valid \\
\hline 2 & Hanya mengisi klik simpan & Semua field terisi & Sistem dapat mengakses masuk & $\begin{array}{l}\text { Sesuai } \\
\text { harapan }\end{array}$ & Valid \\
\hline 3 & $\begin{array}{l}\text { Mengisi semua field yang } \\
\text { ada }\end{array}$ & Semua field di isi & Sistem menerima akses & $\begin{array}{l}\text { Sesuai } \\
\text { Harapan }\end{array}$ & Valid \\
\hline 4 & $\begin{array}{l}\text { Mengisi hanya dengan } 5 \\
\text { field }\end{array}$ & $\begin{array}{l}\text { No. agenda : } \\
12341, \text { tgl. Agenda } \\
: 6 \text { agustus } 2019, \\
\text { no surat : } 12351, \\
\text { Pengirim : Pt bumi } \\
\text { reza, hal : penting }\end{array}$ & $\begin{array}{l}\text { Sistem akan menolak akses masuk dan } \\
\text { menampilkan Pesan "Kesalahan pada } \\
\text { pengisian form (masih kosong)" }\end{array}$ & $\begin{array}{l}\text { Sesuai } \\
\text { harapan }\end{array}$ & Valid \\
\hline
\end{tabular}

\section{KESIMPULAN}

Dari pembahasan diatas dapat dianalisa bahwa sebuah organisasi/ perusahaan sudah sangat tidak layak mengunakan sisten konvensional dalam pengelolaan surat menyuratnya diera informasi saat ini karena sifat pendataan masih dilakukan pencatatan biasa dan belum terolah secara maksimal terutama untuk, pencatatan, pencarian surat surat yang sudah pernah diterbitkan atau surat surat yang sudah pernah diterima. Dengan solusi yang diusulkan adalah pengunaan system informasi agar dapat mengelola data surat, baik surat masuk maupun surat keluar sehingga surat-surat tersebut dapat dicari kapan saja dengan cepat apabila diperlukan.

\section{REFERENSI}

Ferdinandus, Sandy, H. W. (2012). Perancangan Aplikasi Surat Masuk Dan Surat Keluar Pada PT. PLN (Persero) Wilayah Suluttenggo. American Journal of Germanic Linguistics and Literatures, 3(2), 161-174. https://doi.org/10.1017/S10408207000006 9X

Haviluddin. (2013). Summary for Policymakers. Memahami Penggunaan UML (Unified Modelling Language) HAVILUDDIN Program,
$9(2)$,

1-6. https://doi.org/10.1017/CB097811074153 24.004

Priyadi, D. A., \& Lestari, E. W. (2018). Perancangan Sistem Informasi Pelayanan Surat Menyurat Pada Kantor Desa Tanjungsari Kutowinangun Kebumen Berbasis Desktop. Jurnal Teknik Komputer, IV(2), 84-91. https://doi.org/10.31294/jtk.v4i2.3444

Saputra, K. A., \& Famukhit, M. L. (2014). Perancangan Sistem Informasi Pengelolaan Surat Masuk Dan Surat Keluar Pada MTs Guppi Jetiskidul. IJNS - Indonesian Journal on Networking and Security, 3(4). https://doi.org/10.1123/IJNS.V3I4.979

Sasongko, J., \& Diartono, D. A. (2009). Rancang Bangun Sistem Informasi Manajemen Surat, XIV(2), 137-145.

Sugiharti, E., \& Triliani, S. E. (2015). Perancangan Aplikasi Surat Masuk dan Keluar pada PT. Angkasa Pura 1 Semarang. Scientific Journal of Informatics, 1(1), 39-52. https://doi.org/10.15294/sji.v1i1.3640

Suherman, Y. (2017). Sistem Informasi Kearsipan Tata Kelola Surat Pada Kantor Inspeksi BRI Kota Padang. Jurnal RESTI (Rekayasa Sistem Dan Teknologi Informasi), 1(1), 26-33. https://doi.org/10.29207/resti.v1i1.7 